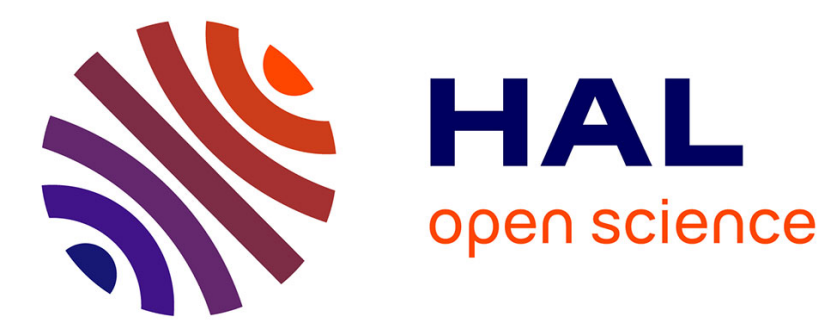

\title{
Observation of acoustically induced modulation instability in a Brillouin photonic crystal fiber laser
}

Birgit Stiller, Thibaut Sylvestre

\section{To cite this version:}

Birgit Stiller, Thibaut Sylvestre. Observation of acoustically induced modulation instability in a Brillouin photonic crystal fiber laser. Optics Letters, 2013, 38, pp.1570 - 1572. hal-00838444

\section{HAL Id: hal-00838444 \\ https://hal.science/hal-00838444}

Submitted on 25 Jun 2013

HAL is a multi-disciplinary open access archive for the deposit and dissemination of scientific research documents, whether they are published or not. The documents may come from teaching and research institutions in France or abroad, or from public or private research centers.
L'archive ouverte pluridisciplinaire HAL, est destinée au dépôt et à la diffusion de documents scientifiques de niveau recherche, publiés ou non, émanant des établissements d'enseignement et de recherche français ou étrangers, des laboratoires publics ou privés. 


\title{
Observation of acoustically-induced modulation instability in a Brillouin photonic crystal fiber laser
}

\author{
Birgit Stiller* and Thibaut Sylvestre \\ Institut FEMTO-ST, Département d'Optique, UMR 6174 CNRS-Université de Franche-Comté, 25000 Besançon, France \\ Corresponding authors: birgit.stiller@mpl.mpg.de, thibaut.sylvestre@univ-fcomte.fr
}

Compiled April 3, 2013

\begin{abstract}
We report the experimental observation of self-induced modulation instability in a Brillouin fiber laser made with a solid-core photonic crystal fiber with strong anomalous dispersion. We identify this modulation instability as the result of parametric amplification of optical sidebands generated by guided acoustic modes within the core of the photonic crystal fiber. It is further shown that modulation instability leads to passive harmonic mode-locking and to the generation of picosecond pulse train at a repetition rate of $1.15 \mathrm{GHz}$, which matches to the acoustic frequency of the fundamental acoustic mode of the photonic crystal fiber. (C) 2013 Optical Society of America
\end{abstract}

OCIS codes: $190.4370,060.3510,060.5295,290.5830$

Brillouin fiber lasers (BFLs) are attractive and simple versatile laser sources that provide high spectral purity and weak relative intensity noise in almost any wavelength in the near infrared region [1-4]. They were developed for applications requiring narrow linewidth lasers such as coherent optical communication, coherent radar detection, and microwave photonics [5-7]. BFLs are all-fiber ring resonators wherein a continuous pump wave near $1.55 \mu \mathrm{m}$ is converted into a backward downfrequency shifted Stokes radiation through stimulated Brillouin scattering (SBS). Single-longitudinal mode operation with sub-kHz linewidth can be readily achieved thanks to the very narrow gain band of the Brillouin spectrum $[1,3]$. Despite these advances, instabilities of the laser output intensity have often been observed and were investigated in detail in order to either mitigate them or, vice versa, to lock them for optical pulse generation. Pulse formation in BFLs have indeed been reported in the past as the result of the excitation of low-frequency transverse acoustic modes in optical fibers [8-10]. Also known as guided acoustic wave Brillouin scattering (GAWBS), two different types of transverse acoustic modes, radial and torso-radial modes, have been observed for standard single-mode fibers [11]. In solid-core photonic crystal fibers (PCF), GAWBS was recently found to be highly suppressed in the lower $\mathrm{MHz}$ frequency region $[12,13]$ and strongly enhanced for highfrequency acoustic modes trapped within the fiber core by the air-hole microstructure $[13,14]$. As GAWBS is similar to frequency modulation, this feature is interesting for harmonic frequency modulation (FM) modelocking and has recently been implemented in an Erbium doped fiber laser including a PCF [15].

In this letter we investigate a BFL made with a long $\mathrm{PCF}$ and report the observation of self-induced modulation instability (MI) and pulse train generation. We show in particular that, above a certain pump power level, MI

* Present address: Max Planck Institute for the Science of Light, Günther-Scharowsky-Str. 1, 91058 Erlangen, Germany manifests in the laser cavity from high-frequency guided acoustic modes in the core of the PCF. It is further shown that MI leads to passive harmonic mode-locking along with the generation of 430 picosecond pulse train at a repetition rate of $1.15 \mathrm{GHz}$, matching the acoustic frequency of the fundamental elastic mode tightly confined in the PCF core. In other words, passive modelocking of the laser modes is achieved outside the Brillouin gain spectrum by modulation instability induced from the transverse acoustic mode.

The experimental setup of our BFL is shown schematically in Fig. 1. The pump laser is a linearly-polarized continuous-wave (cw) distributed feedback (DFB) fiber laser emitting at $\lambda_{P}=1.55 \mu \mathrm{m}$ and with a $15 \mathrm{kHz}$ linewidth. The output is then amplified by a highpower Erbium-doped fiber amplifier (EDFA, $33 \mathrm{dBm}$ ) and a band-pass filter ( $1 \mathrm{~nm}$ width) at $\lambda_{P}$ is used to suppress amplified spontaneous emission (ASE) coming from the EDFA. The ring cavity consists of a $100 \mathrm{~m}$-long PCF with the following characteristics at $1.55 \mu \mathrm{m}$ : effective mode area $A_{\mathrm{eff}}=5.3 \mu \mathrm{m}^{2}$, linear loss $\alpha=5.4 \mathrm{~dB} / \mathrm{km}$ and group-velocity dispersion (GVD) pa-

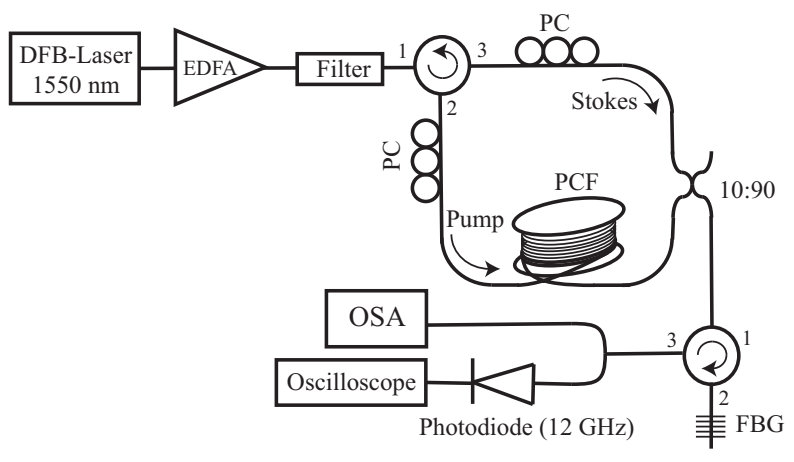

Fig. 1. Experimental setup of the BFL. EDFA: Erbiumdoped fiber amplifier; OSA: Optical spectrum analyser (20 MHz resolution); PC: Polarization controller; FBG: fiber Bragg grating; PCF: photonic crystal fiber. 
rameter $D=115.6 \mathrm{ps} / \mathrm{nm} / \mathrm{km}$ at $1550 \mathrm{~nm}$. The SEM image of the microstructure is shown in the inset of Fig. 3(a). It consists of a standard triangular lattice with a core diameter $\mathrm{d}_{c}=2.7 \mu \mathrm{m}$, holes diameter $\mathrm{d}=$ $2.55 \mu \mathrm{m}$ and a pitch $\Lambda=2.9 \mu \mathrm{m}(\mathrm{d} / \Lambda=0.88)$. Two polarization controllers help for adjusting the polarization of the Stokes and pump waves and for minimizing the laser threshold. A 10/90 tap fiber coupler is inserted into the cavity to extract the backward Brillouin Stokes radiation resonating in the cavity. A tunable fiber Bragg grating with $10 \mathrm{GHz}$ bandwidth filters out the residual pump radiation. The laser output is finally monitored with a high-resolution optical spectrum analyzer (OSA) with $20 \mathrm{MHz}$ resolution and a $12 \mathrm{GHz}$ bandwidth realtime oscilloscope with a fast photodiode.

We first performed a measurement of the laser output power using a power meter to estimate the laser threshold. Figure 2(a) shows the laser output power versus the input one. As it can be seen, we measured a laser threshold of about $14 \mathrm{dBm}$ and a power slope of $9.1 \mathrm{~dB}$. A maximum output power of $0 \mathrm{dBm}$ at the $10 \%$ tab fiber coupler is obtained which corresponds to $10 \mathrm{dBm}$ laser power in the cavity. Note that the conversion efficiency is relatively weak mainly due to splicing losses between our PCF and the fiber optics components. The optical spectra of the laser output from input pump power $11 \mathrm{dBm}$ to $31 \mathrm{dBm}$ have been recorded and three examples at power $\mathrm{P}_{\mathrm{in}}=13.6 \mathrm{dBm}, \mathrm{P}_{\mathrm{in}}=29.7 \mathrm{dBm}$ and $\mathrm{P}_{\mathrm{in}}=30.8 \mathrm{dBm}$ are shown in Fig. 2(b,c,d). As expected, a narrow linewidth Stokes radiation can be observed which is shifted by $10.89 \mathrm{GHz}$ with respect to the pump and whose output power rises with increasing pump power. However, in the high power region an unexpected behaviour is observed in Fig. 2(d). A frequency comb with $1.15 \mathrm{GHz}$ frequency spacing around the Stokes wave occurs with up to 10 sidebands for each side. Also around
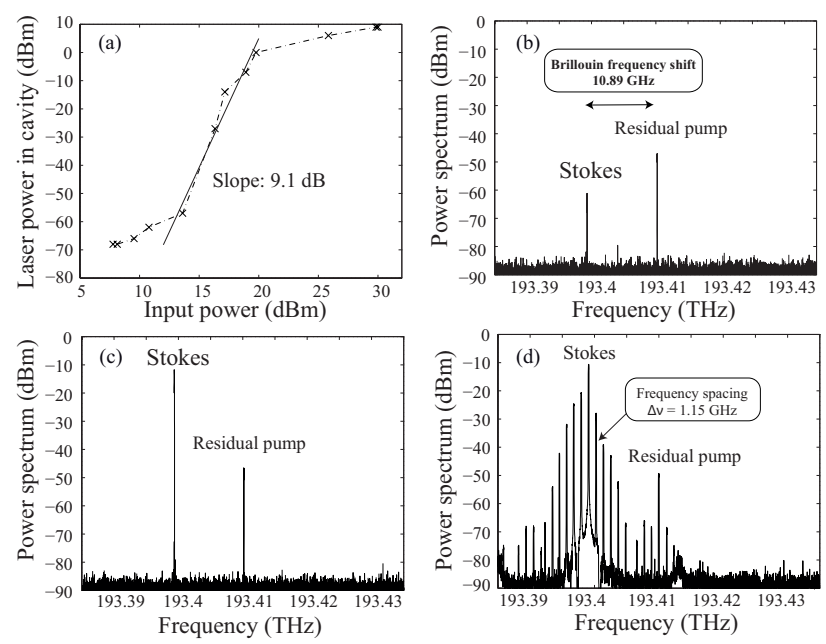

Fig. 2. (a) Brillouin laser output power with increasing input pump power; optical spectra of the laser output for pump power (b) $\mathrm{P}_{\mathrm{in}}=13.6 \mathrm{dBm},(\mathrm{c}) \mathrm{P}_{\mathrm{in}}=29.7 \mathrm{dBm}$ and (d) $\mathrm{P}_{\mathrm{in}}=30.8 \mathrm{dBm}$. The resolution is $20 \mathrm{MHz}$.

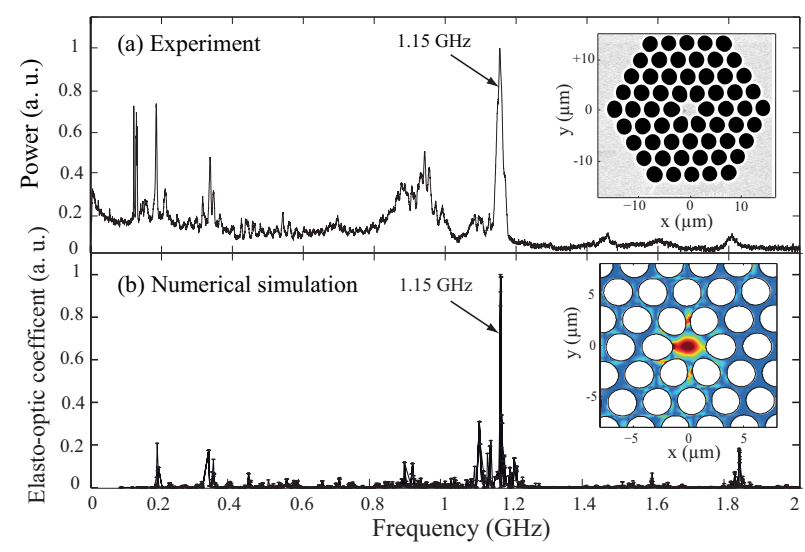

Fig. 3. (a) Experiment: Radio-frequency spectrum recorded at the PCF output showing the GAWBS spectrum with a dominant peak at $1.15 \mathrm{GHz}$. Inset: PCF cross section; (b) Theory: Numerical simulations of the elasto-optic coefficient. Inset: strain energy density of the acoustic mode at $1.15 \mathrm{GHz}$.

the pump wave this phenomenon can be seen but it is filtered by the fiber Bragg grating. The frequency comb is highly polarization dependent in the laser cavity and yet difficult to stabilize. With a spacing of $1.15 \mathrm{GHz}$, the optical sidebands are far from the Brillouin gain spectrum which has a natural linewidth of only $25 \mathrm{MHz}$ in silica. Consequently, these laser modes cannot be accounted by the Brillouin cavity gain, as in Ref. [10]. These sidebands actually comes from the transverse fundamental acoustic mode that is generated in the core of the PCF, as that shown in Figs. 3(a,b) both experimentally and numerically. More specifically, Fig. 3(a) shows the forward Brillouin spectrum recorded at the PCF output. Several GAWBS frequencies can be seen from $100 \mathrm{MHz}$ to more than $1.8 \mathrm{GHz}$ and we can clearly identify a strong acoustic mode at a resonance frequency of $1.15 \mathrm{GHz}$, corresponding to the frequency comb spacing observed in Fig. 2(d). To identify this acoustic mode, we performed numerical simulations based on a finite element method (for detailed calculations, see Refs [16, 17]). Figure 3(b) shows the computed elasto-optic coefficient versus the frequency with a dominant peak at $1.15 \mathrm{GHz}$. The strain energy density distribution at the acoustic frequency of $1.15 \mathrm{GHz}$ is also plotted in the inset of Fig. 3(b). It can clearly be seen that this acoustic mode is spatially localized within the fiber core and results from radial compression and dilatation of the air-hole microstructure. This acoustic mode is identified as the fundamental phonon of the radial R01 mode in the numerical simulation. The acoustic wave scatters the light and generates a narrow line at $1.15 \mathrm{GHz}$ in the Fourier spectrum, as that observed in Fig. 3(a). Since our PCF exhibits a strong anomalous dispersion at $1.55 \mu \mathrm{m}$, MI can be efficiently seeded in the cavity laser by these sidebands. We have indeed checked that the phase-matching condition for these sidebands is almost satisfied [18]. This equation reads as $\Delta \beta=\beta_{2} \Omega^{2}+2 \gamma P_{S}=0$, where $\beta_{2}$ is the GVD coefficient (here $-1.47 \cdot 10^{-25} \mathrm{~s}^{2} \mathrm{~m}^{-1}$ ), $\gamma$ is the nonlinear co- 

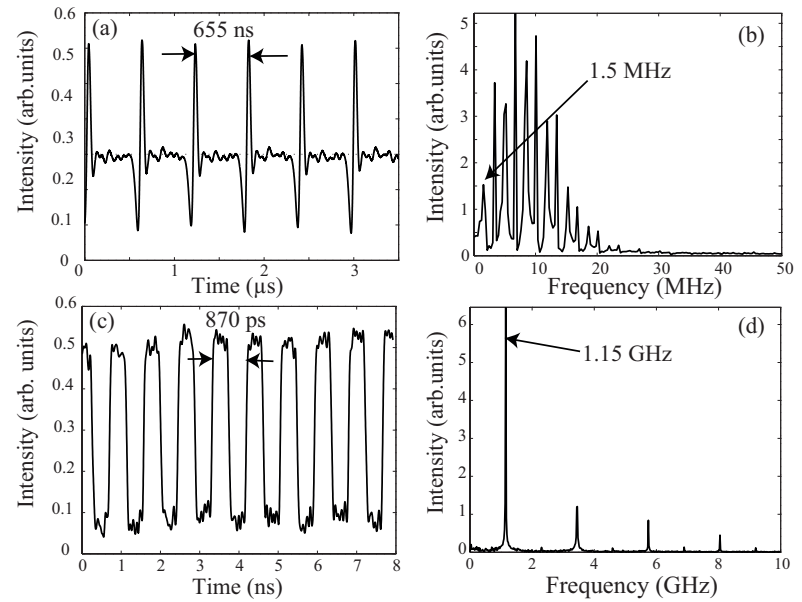

Fig. 4. Oscilloscope traces of the laser output showing the pulse formation with (a) $655 \mathrm{~ns}$ repetition rate and $38 \mathrm{~ns}$ width at $29.7 \mathrm{dBm}$, (b) 870 ps repetition rate and $430 \mathrm{ps}$ width at $30.8 \mathrm{dBm}$; $(\mathrm{c}, \mathrm{d}) \mathrm{FFT}$ of the time traces in $(\mathrm{a}, \mathrm{b})$.

efficient of $16.8 \mathrm{~W}^{-1} \mathrm{~km}^{-1}$ and $P_{S}$ is the Brillouin Stokes power in the fiber cavity. From the above equation, we find a MI frequency $\nu_{\mathrm{MI}}=\frac{1}{2 \pi} \sqrt{\frac{2 \gamma P_{S}}{\left|\beta_{2}\right|}}$ of $7.6 \mathrm{GHz}$, which corresponds to the maximum of the MI gain spectrum. This value is in the same order of magnitude as the acoustic frequency at $1.15 \mathrm{GHz}$. Consequently, a large number of higher-order harmonics sidebands, up to the 6 th and 7th order, are within the MI gain spectrum and can be amplified. Encouraged by these results, we also tested the ability of our PCF-based Brillouin laser to get harmonically phase-locked and to generate optical pulse train at high repetition rates. The observed intensity fluctuations on the oscilloscope and their Fast Fourier Transform (FFT) are depicted in Fig. 4. At $29.7 \mathrm{dBm}$ pump power, we observe stable dark-bright pulse trains with $38 \mathrm{~ns}$ linewidth and $655 \mathrm{~ns}(1.53 \mathrm{MHz})$ repetition rate. This corresponds to the well-known BFL oscillation [10]. The repetition rate refers to the second harmonic of the cavity mode spacing calculated by $\nu=c /(L \cdot n)$ with a pulse linewidth corresponding to the Brillouin gain spectrum. L is the cavity length, c the velocity of light, and $\mathrm{n}$ the effective index. The corresponding FFT shows frequency peaks from $1.5 \mathrm{MHz}$ with $1.5 \mathrm{MHz}$ spacing up to around $20 \mathrm{MHz}$. Increasing the input pump power to $30.8 \mathrm{dBm}$ and adjusting the polarization leads to a change in the pulse dynamics. Fig. 4(c) shows the generation of 430 ps-long square pulses with a period of $870 \mathrm{ps}$. The corresponding repetition rate is $1.15 \mathrm{GHz}$ (750th harmonic mode locking) in good agreement with the resonant frequency of the fundamental acoustic mode guided in the PCF core. More precisely, the FFT plotted in Fig. 4(d) shows well distinct frequency peaks at $1.15 \mathrm{GHz}$ and multiples. However, the contrast of the time trace is 60 times smaller than for the other pulse regime.

In conclusion we reported the observation of modulation instability and pulse train generation in a $\mathrm{BFL}$ including a long PCF. We have shown that modulation instability starts from high-frequency transverse acoustic modes guided in the core of the PCF. This effect leads to passive harmonic mode-locking of the fiber ring laser at a repetition rate of $1.15 \mathrm{GHz}$, corresponding to the resonant acoustic frequency of the fiber core. Note that the laser dynamics presented here is nearly similar to that of the self-induced modulation instability fiber laser, except that modulation instability is triggered by acoustic waves at lower frequency $[19,20]$.

The authors thank Jean-Charles Beugnot for providing Fig. 3(a) and the European Interreg IV A program and ANR LABEX action project for funding.

\section{References}

1. K. O. Hill, B. S. Kawasaki, and D. C. Johnson, Appl. Phys. Lett. 28, 608 (1976).

2. S. P. Smith, F. Zarinetchi, and S. Ezekiel, Opt. Lett. 16(6), 393 (1991).

3. J. Geng, S. Staines, Z. Wang, J. Zong, M. Blake, and S. Jiang, IEEE Photon. Technol. Lett. 18, 1813 (2006).

4. K. H. Tow, Y. Leguillon, P. Besnard, L. Brilland, J. Troles, P. Toupin, D. Mchin, D. Trgoat, and S. Molin, Opt. Lett. 37, 1157 (2012).

5. G. J. Cowle and D. Y. Stepanov, IEEE Photon. Tech. Lett. 8(11), 1465 (1996).

6. H. Ahmad, S. Shahi, and S.W. Harun, Laser Phys. 20, 716- (2010).

7. V. V. Spirin, C. A. Lopez-Mercado, P. Megret, and A. A. Fotiadi, Laser Phys. Lett. 9, 377 (2012).

8. A. N. Pilipetskii, E. A. Golovchenko, and C. R. Menyuk, Opt. Lett. 20(8), 907 (1995).

9. S. Gray, A. B. Grudinin, W. H. Loh, and D. N. Payne, Opt. Lett. 20, 189 (1995).

10. I. Bongrand, C. Montes, E. Picholle, J. Botineau, A. Picozzi, G. Cheval, and D. Bahloul, Opt. Lett.26(19), 1475 (2001).

11. R. M. Shelby, M. D. Levenson, and P. W. Bayer, Phys. Rev. B 31, 5244 (1985).

12. D. Elser, U. L. Andersen, A. Korn, O. Glöckl, S. Lorenz, C. Marquardt, and G. Leuchs, Phys. Rev. Lett. 97, 133901 (2006).

13. J.-C. Beugnot, T. Sylvestre, H. Maillotte, G. Mélin, and V. Laude, Opt. Lett. 32, 17 (2007).

14. P. Dainese, P. St. J. Russell, G. S. Wiederhecker, N. Joly, H. L. Fragnito, V. Laude, and A. Khelif, Opt. Express 14, 4141 (2006).

15. M. S. Kang, N. Y. Joly, and P. St. J. Russell, Opt. Lett. 38, 561 (2013).

16. B. Stiller, M. Delqué, J.-C. Beugnot, M. W. Lee, G. Mélin, H. Maillotte, V. Laude, and T. Sylvestre, Opt. Express 19, 7689 (2011).

17. E. Carry, J.-C. Beugnot, B. Stiller, M. W. Lee, H. Maillotte, and T. Sylvestre, Appl. Opt., 50, 35, 6543 (2011).

18. G. P. Agrawal, Nonlinear Fiber Optics, New York, Academic Press, 2007.

19. E. Yoshida and M. Nakazawa, Opt. Lett. 22, 1409 (1997).

20. T. Sylvestre, S. Coen, P. Emplit, and M. Haelterman, Opt. Lett. 27, 482 (2002). 


\section{References}

1. K. O. Hill, B. S. Kawasaki, and D. C. Johnson, "CW Brillouin laser," Appl. Phys. Lett. 28, 608-610 (1976).

2. S. P. Smith, F. Zarinetchi, and S. Ezekiel, "Narrowlinewidth stimulated Brillouin fiber laser and applications," Opt. Lett. 16(6), 393-395 (1991).

3. J. Geng, S. Staines, Z. Wang, J. Zong, M. Blake, and S. Jiang, "Highly stable low-noise Brillouin fiber laser with ultranarrow spectral linewidth," IEEE Photon. Technol. Lett. 18, 1813-1815 (2006).

4. K. H. Tow, Y. Leguillon, P. Besnard, L. Brilland, J. Troles, P. Toupin, D. Mchin, D. Trgoat, and S. Molin, "Relative intensity noise and frequency noise of a compact Brillouin laser made of As38Se62 suspended-core chalcogenide fiber," Opt. Lett. 37, 1157-1159 (2012).

5. G. J. Cowle and D. Y. Stepanov, "Multiple wavelength generation with Brillouin/Erbium fiber lasers," IEEE Photon. Tech. Lett. 8(11), 1465-1467 (1996).

6. H. Ahmad, S. Shahi, and S.W. Harun, "Bismuth-based erbium-doped fiber as a gain medium for L-band amplification and Brillouin fiber laser," Laser Phys. 20, 716719 (2010)

7. V. V. Spirin, C. A. Lopez-Mercado, P. Megret, and A. A. Fotiadi, "Single-mode Brillouin fiber laser passively stabilized at resonance frequency with self-injection locked pump laser," Laser Phys. Lett. 9(5), 377-380 (2012).

8. A. N. Pilipetskii, E. A. Golovchenko, and C. R. Menyuk, "Acoustic effect in passively mode-locked fiber ring lasers," Opt. Lett. 20(8), 907-909 (1995).

9. S. Gray, A. B. Grudinin, W. H. Loh, and D. N. Payne, "Femtosecond harmonically mode-locked fiber laser with time jitter below 1 ps," Opt. Lett. 20(2), 189-191 (1995).

10. I. Bongrand, C. Montes, E. Picholle, J. Botineau, A. Picozzi, G. Cheval, and D. Bahloul, "Soliton compression in Brillouin fiber lasers," Opt. Lett.26(19), 1475-1477 (2001).

11. R. M. Shelby, M. D. Levenson, and P. W. Bayer, "Guided acoustic-wave Brillouin scattering," Phys. Rev. B 31, 5244-5252 (1985).

12. D. Elser, U. L. Andersen, A. Korn, O. Glöckl, S. Lorenz, C. Marquardt, and G. Leuchs, "Reduction of guided acoustic wave Brillouin scattering in photonic crystal fibers," Phys. Rev. Lett. 97, 133901 (2006).

13. J.-C. Beugnot, T. Sylvestre, H. Maillotte, G. Mélin, and V. Laude, "Guided acoustic wave Brillouin scattering in photonic crystal fibers," Opt. Lett. 32, 17-19 (2007).

14. P. Dainese, P. St. J. Russell, G. S. Wiederhecker, N. Joly, H. L. Fragnito, V. Laude, and A. Khelif, "Ramanlike light scattering from acoustic phonons in photonic crystal fiber," Opt. Express 14, 4141-4150 (2006).

15. M. S. Kang, N. Y. Joly, and P. St. J. Russell, "Passive mode-locking of fiber ring laser at the 337th harmonic using gigahertz acoustic core resonances," Opt. Lett. 38, 561-563 (2013).

16. B. Stiller, M. Delqu, J.-C. Beugnot, M. W. Lee, G. Mlin, H. Maillotte, V. Laude, and T. Sylvestre, "Frequencyselective excitation of guided acoustic modes in a photonic crystal fiber," Opt. Express 19, 7689-7694 (2011).

17. E. Carry, J.-C. Beugnot, B. Stiller, M. W. Lee, H. Maillotte, and T. Sylvestre, "Temperature coefficient of the high-frequency guided acoustic mode in a photonic crystal fiber," Appl. Opt., 50(35), 6543-6547 (2011).
18. G. P. Agrawal, Nonlinear Fiber Optics, New York, Academic Press, 2007.

19. E. Yoshida and M. Nakazawa, "Low-threshold $115-\mathrm{GHz}$ continuous-wave modulational-instability erbium-doped fiber laser," Opt. Lett. 22, 1409-1411 (1997).

20. T. Sylvestre, S. Coen, P. Emplit, and M. Haelterman, "Self-induced modulational instability laser revisited: normal dispersion and dark-pulse train generation," Opt. Lett. 27, 482-484 (2002). 